\title{
Contact Stress Analysis of Motorcycle Transmission Gears Using Autodesk Inventor
}

\author{
Taufiq Hidayat ${ }^{1}$, Masruki Kabib ${ }^{2}$, Rochmad Winarso ${ }^{3}$, Hera Setiawan ${ }^{4}$, Bachtiar Setya \\ Nugraha $^{5}$, Qomaruddin 6 \\ \{taufiq.hidayat@umk.ac.id, masruki.kabib@umk.ac.id,rochmad.winarso@umk.ac.id\} \\ Mechanical Engineering Department, Universitas Muria Kudus, Kudus, Central Java, Indonesia ${ }^{123456}$
}

\begin{abstract}
Almost all components have mechanical contacts on the surface while in working condition. Contacts that occur between components can be static contact, rolling contact, or sliding contact. Motorcycle have a complex transmission gears. In this study, the transmission gears analyzed are pair of second-level gears from a motorcycle. Software used is Autodesk Inventor. The study begin with the design of gears, then a stress analysis performed to generate Von Mises stress, displacement and contact pressure. The maximum torque of the motorcycle is $7256.921 \mathrm{Nmm}$. The gear material is AISI 4142 alloy steel which has a yield strength of $1619 \mathrm{MPa}$. The consequences have been offered and finite element analysis outcomes had been compared with mathematical calculations, wherever available.
\end{abstract}

Keywords: gears contact, Von Mises, strain, displacement, contact pressure.

\section{Introduction}

Elements of power transfer are found in many fields in modern life today. Almost all mechanical devices have at least one or two elements, motor vehicles have gears as power transmission; the washing machine has a pulley to rotate the drum; computer printers have gears, cam and pulleys to move paper and set up printing heads; photocopiers and Automated Teller Machines have many power transfer elements in each section. Generally, the transfer element is divided into two, namely power transfer and motion transmission.

The gears and gear transmissions are used to change the movement characteristics, either reversing the rotation to linear movement, linear to rotation, or just changes to the torque and speed of the shaft (lap to round). Transmission gears include old inventions that have evolved over the centuries in terms of profile and transmission complexity.

The contact area between the gears has a rectangular shape and can be grouped in the line contact problems as shown in figure 1. Contacts that occur on the gear are in the form of nonformal contact and are included in elastic deformation. Non-formal contact and elastic deformation are categorized in line contact Elasto Hydrodynamic Lubrication (EHL) [1].

A number of researchers conducted simulations and analyzed the contact stresses on the gears. Mr. Bharat Gupta [2] analyzed the contact stresses of spur gears with a variety of modules. He did a contact stress calculation using the Hertzian equation and compared it with the results obtained from the simulation using ANSYS. Comparison of the results can be seen in Figure 2.

ICCSET 2018, October 25-26, Kudus, Indonesia

Copyright (C) 2018 EAI

DOI 10.4108/eai.24-10-2018.2280532 


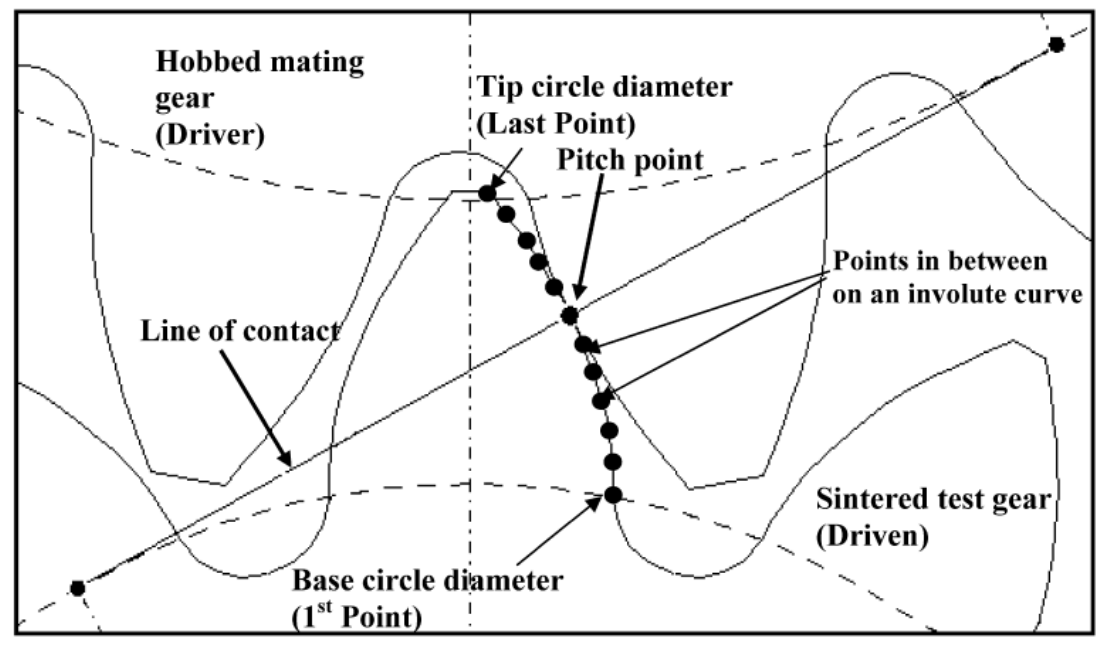

Fig. 1. Gears contacts.

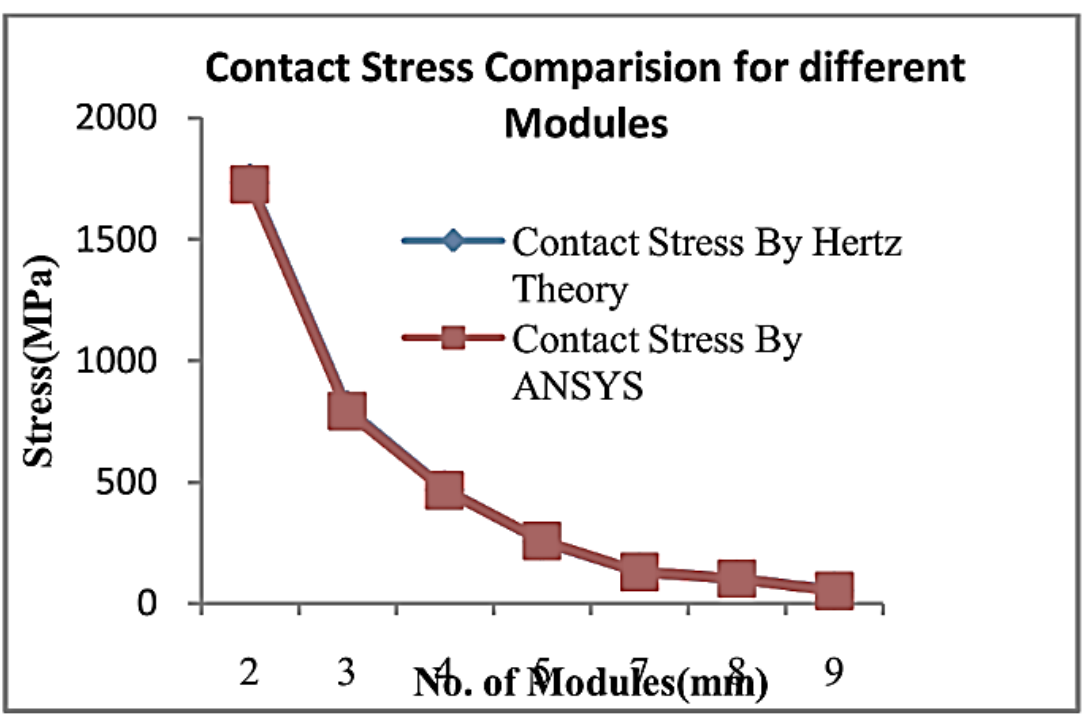

Fig. 2. Contact stresses comparison for different modules.

Analysis of spur and helical gear stresses on rotation was done by Seok-Chul Hwang [3]. The variation of the contact stress during rotation was compared with the contact stress at the lowest point of single-tooth contact (LPSTC) and the AGMA (American Gear Manufacturers Association) equation for the contact stress. In their study, it can be seen that the gear design that considers the contact stress in a pair of mating gears was more severe than that of the 
AGMA standard. Simulation results for spur gears are shown in figure 3, while the helical gears are shown in figure 4.

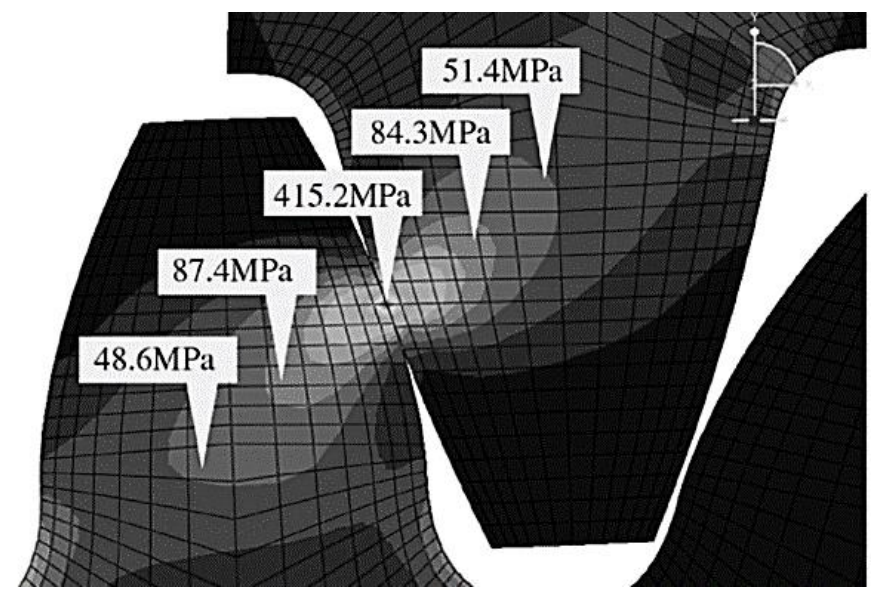

Fig. 3. Contact stresses of spur gears.

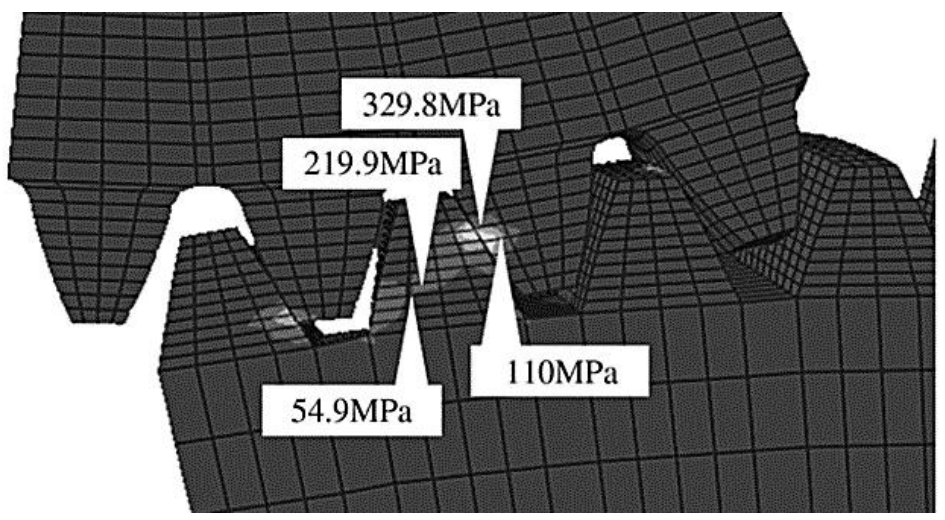

Fig. 4. Contact stresses of helical gears.

\section{Methodology}

Research begins with learning and discussion of another research results and previous literature. Then generates gear design, simulation and stress analysis using Autodesk Inventor [4]. The discussion is conducted to analyze the simulation results. 


\subsection{Generates gear design using CAD software}

The transmission gear design is made with Autodesk Inventor. The gears consist of main gear and counter gear. Main gear is a spur gear drive. Consisting of 17 teeth and modules of 1.75. While the counter gear is spur gear driven. Consists of 29 pieces of gear teeth with modules of 1.75. The design of 3-dimensional gears by Autodesk Inventor and the results are shown by figure 5 for main gear and counter gear. The simulated gear parameters are shown in table 1.

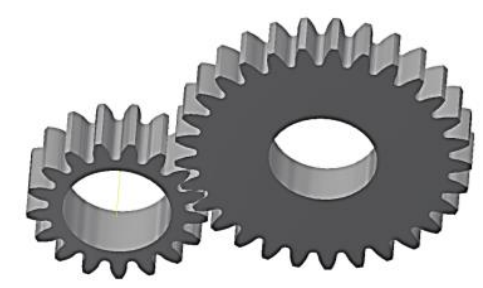

Fig. 5. Main gear and counter gear.

Table 1. Gear parameters.

\begin{tabular}{lll}
\hline Parameters & Main gear & Counter gear \\
\hline Pitch diameter & $29.75 \mathrm{~mm}$ & $50.75 \mathrm{~mm}$ \\
Module & $1.75 \mathrm{~mm}$ & $1.75 \mathrm{~mm}$ \\
Number of Teeth & 17 & 29 \\
Tooth width & $11 \mathrm{~mm}$ & 8.5 \\
Shaft diameter & $20 \mathrm{~mm}$ & $20 \mathrm{~mm}$ \\
Pressure Angle & $20^{\circ}$ & $20^{\circ}$ \\
\hline
\end{tabular}

\subsection{Modelling and Simulation}

The modeling procedure follows the procedures in the Autodesk Inventor, which are:

\subsubsection{Assign material specification}

Specifies the type of material on the part where it can be selected and adds appropriate material properties into the Inventor Material library. If the material in the library does not find the desired material, it can be added and edited in accordance with the material properties.

Gear is made from alloy steel AISI 4142 material that has a yield strength of $1619 \mathrm{MPa}$, good toughness and good strength. The property of the gear material is shown in table 2 .

Table 2. Material properties.

\begin{tabular}{ll}
\hline Properties & Value \\
\hline Density & $7.85 \mathrm{~g} / \mathrm{cm}^{3}$ \\
Young's Modulus & $207 \mathrm{Gpa}$ \\
Ultimate Tensile Strength & $2446 \mathrm{MPa}$ \\
Yield Strength & $1619 \mathrm{MPa}$ \\
Poisson ratio & 0.33 \\
Shear modulus & $77.8195 \mathrm{GPa}$ \\
\hline
\end{tabular}


Maximum contact pressure is calculated using the Hertzian formula as follows [2]:

$$
p_{p}=y_{m} \times y_{p} \sqrt{\frac{F_{t}}{b \times d_{1}} \times \frac{u+1}{u}}
$$

$F_{t}$ is force, $b$ is tooth width, $d_{l}$ is pitch diameter of main gear, $u$ is $d_{2} / d_{l}, y_{m}$ is the material coefficient, which is calculated using the formula:

$$
y_{m}=\sqrt{0.35 \times \frac{2 \times E_{1} \times E_{2}}{E_{1}+E_{2}}}
$$

$y_{p}$ is the pitch point coefficient, which is calculated using the formula:

$$
y_{p}=\sqrt{\frac{1}{\cos ^{2} \alpha x \tan \alpha}}
$$

From equation 1, 2 and 3, we can calculate the maximum pressure contact, as follows:

$$
\begin{gathered}
y_{m}=\sqrt{0.35 x \frac{2 \times 207 \times 10^{3} \times 207 \times 10^{3}}{207 \times 10^{3}+207 \times 10^{3}}} \\
y_{m}=269.16 \\
y_{p}=\sqrt{\frac{1}{\cos ^{2} 20 \times \tan 20}} \\
y_{p}=1.64
\end{gathered}
$$

The maximum torque of the motorcycle is $7256.921 \mathrm{Nmm}, T=F_{t} \times r$, so the force is:

$$
\begin{gathered}
F_{t}=\frac{T}{r}=\frac{7256.921 \mathrm{Nmm}}{14.875 \mathrm{~mm}}=487.86 \mathrm{~N} \\
u=\frac{50.75}{29.75}=1.71
\end{gathered}
$$

Hence the maximum pressure is:

$$
\begin{gathered}
p_{p}=269.16 \times 1.64 x \sqrt{\frac{487.86}{11 \times 29.75} \times \frac{1.71+1}{1.71}} \\
p_{p}=678.49 \mathrm{MPa}
\end{gathered}
$$

\subsubsection{Define Constraints}


Specifies the area to limit the position of the part of the movement when a load is given. Pin Constraints, restrictions on rotating parts, pin constraints placed on the shaft holes on both of gears. Then Frictionless Constraints, prevents motion of face in the direction normal to the face. The constraints are selected on the side surface of both of gears.

\subsubsection{Loading}

Provides force and moment parameters on the gear area in accordance with the application. The force is applied on one of the surface of the main gear tooth about $487.86 \mathrm{~N}$. while the moment is placed on the counter gear shaft hole, which is equal to $7256,921 \mathrm{Nmm}$.

\subsubsection{Running the simulation}

In Autodesk Inventor the steps taken for model analysis are simulated by calculating all the parameters that already exist. After the running process is complete, it will come out the results of the simulation of the gears. The results of the simulation are von mises, displacement, and contact pressure. This stress analysis will show which parts are affected by the largest and smallest loading. The area will be marked by the color difference seen on the object. There is a color range that has been detailed on the side of the object. So the color part there are values that will be read on the simulation results.

\section{Results and Discussion}

This study relates to contact stress, contact pressure, displacement, and von mises stress. This calculation is certainly not easy, and must use finite element analysis. Contact pressure is calculated by the formula as above and results in a maximum contact pressure of $678.49 \mathrm{MPa}$. Autodesk Inventor software implements the stress simulation process with finite element method.

The simulation results are shown by the figure 6,7 and 8 for the Von Mises stresses, displacement and contact pressure respectively. 


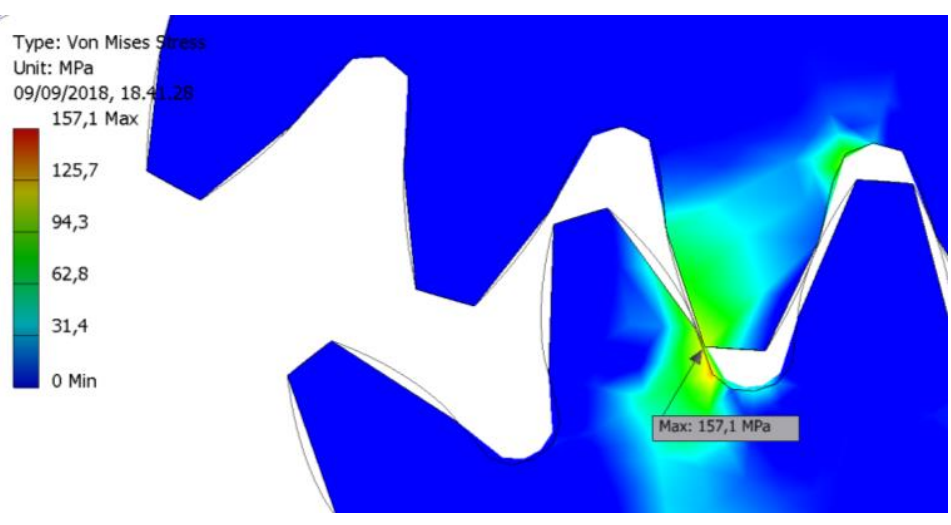

Fig. 6. Von Mises stress.

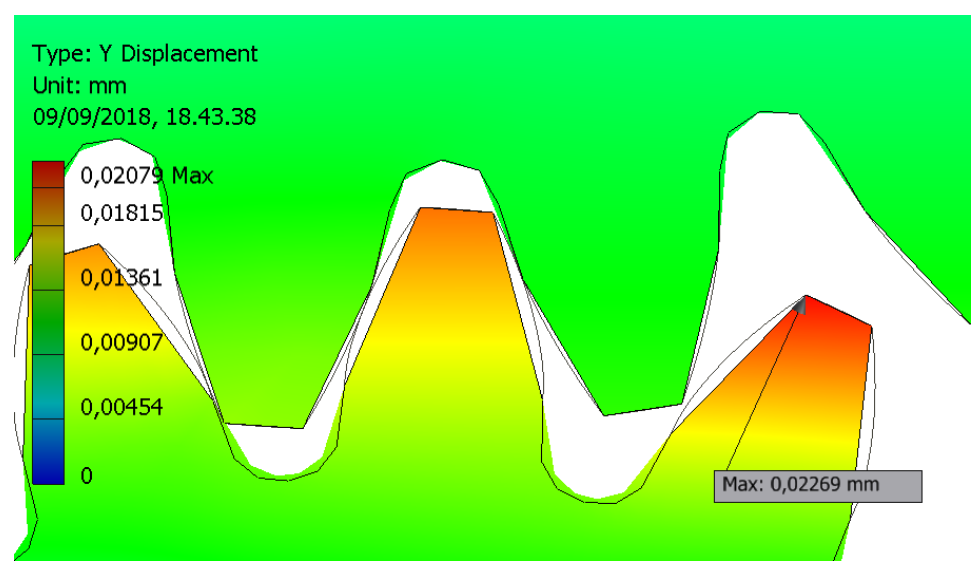

Fig. 7. Displacement on $\mathrm{Y}$ axis direction.

From the figure 6, it can be seen that maximum Von Mises is 157.1 MPa. While the yield strength of AISI 4142 is $1619 \mathrm{MPa}$. So the safety factor is about 10.3 . We can concluded that gears are still in a safe condition.

The maximum displacement on $\mathrm{Y}$ axis direction is $0.02269 \mathrm{~mm}$ (fig. 7). And the maximum contact pressure is $675.4 \mathrm{MPa}$ (fig. 8). If we compare the value of the maximum contact pressure from the calculation result with the value of using Autodesk Inventor simulation, there is a difference of $3.09 \mathrm{Mpa}(0.45 \%)$. These differences can be accepted. 


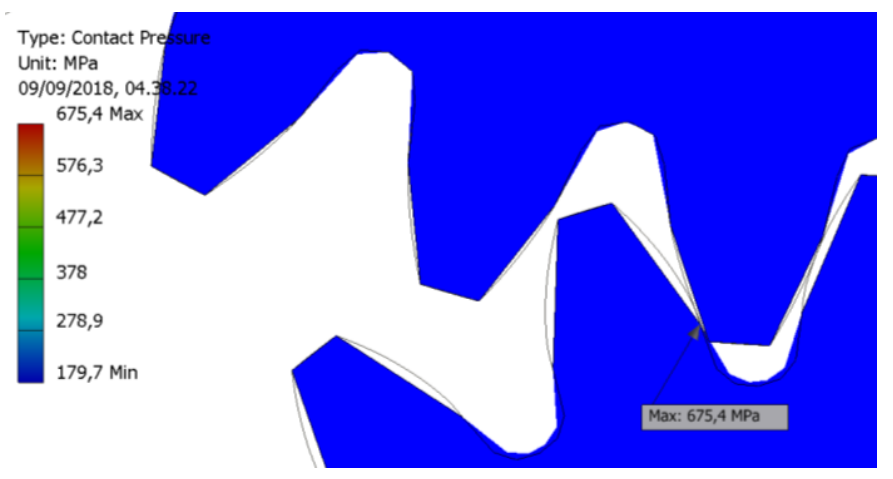

Fig. 8. Contact pressure.

From Ali Raad Hassan research, the maximum contact stress value for this model turned into $587 \mathrm{MPa}$ which obtained by using AGMA, the widely known theoretical calculations method. The stress analysis has been executed via ANSYS software, in which the consequences have been provided through contours and numerical values [5].

\section{Conclusion}

This study used mathematical calculations to calculate the maximum contact pressure and used simulation software to generate maximum Von Mises stress, maximum displacement and maximum contact pressure. From the calculation results obtained a maximum contact pressure of $678.49 \mathrm{MPa}$. While using simulation software, the Von Mises stress is $157.1 \mathrm{MPa}$, the maximum displacement is $0.02269 \mathrm{~mm}$, and the maximum contact pressure is $675.4 \mathrm{MPa}$.

\section{References}

[1] S. Akbarzadeh and M. M. Khonsari, "Experimental and theoretical investigation of running-in," Tribol. Int., 2011.

[2] A. choubey Bharat Gupta, "Contact Stress Analysis of Spur Gear,” Int. J. Eng. Res. Technol., 2012.

[3] S. C. Hwang, J. H. Lee, D. H. Lee, S. H. Han, and K. H. Lee, "Contact stress analysis for a pair of mating gears," Math. Comput. Model., 2013.

[4] AUTODESK INVESTOR, “Autodesk inventor,” [En línea]. Available http//images.autodesk.com/adsk/files/invpro10_detail_bro_us.pdf, 2016.

[5] A. R. Hassan, "Contact stress analysis of spur gear teeth pair," World Acad. Sci. Eng. Technol., 2009. 